\title{
HAND1 loss-of-function mutation contributes to congenital double outlet right ventricle
}

\author{
LI LI $^{12^{2 *}}$, JUAN WANG ${ }^{3 *}$, XING-YUAN LIU ${ }^{4}$, HUA LIU $^{5}$, HONG-YU SHI ${ }^{5}$, XIAO-XIAO YANG ${ }^{5}$, \\ NING LI ${ }^{5}$, YAN-JIE LI ${ }^{5}$, RI-TAI HUANG ${ }^{6}$, SONG XUE $^{6}$, XING-BIAO QIU ${ }^{5}$ and YI-QING YANG ${ }^{5,7,8}$
}

${ }^{1}$ Key Laboratory of Arrhythmias of the Ministry of Education of China, East Hospital, Tongji University School of Medicine;

${ }^{2}$ Research Center for Translational Medicine, and ${ }^{3}$ Department of Cardiology, East Hospital, Tongji University School of Medicine, Shanghai 200120; ${ }^{4}$ Department of Pediatrics, Tongji Hospital, Tongji University School of Medicine, Shanghai 200065; ${ }^{5}$ Department of Cardiology, Shanghai Chest Hospital, Shanghai Jiao Tong University, Shanghai 200030;

${ }^{6}$ Department of Cardiovascular Surgery, Renji Hospital, School of Medicine, Shanghai Jiao Tong University, Shanghai 200127; Departments of ${ }^{7}$ Cardiovascular Research Laboratory, and ${ }^{8}$ Central Laboratory, Shanghai Chest Hospital, Shanghai Jiao Tong University, Shanghai 200030, P.R. China

Received October 3, 2016; Accepted January 5, 2017

DOI: $10.3892 /$ ijmm.2017.2865

\begin{abstract}
Congenital heart defects (CHDs), a wide variety of developmental abnormalities in the structures of the heart and the great thoracic blood vessels, are the most common form of birth defect in humans worldwide. CHDs are accountable for substantial morbidity and are still the leading cause of birth defect-related deaths. Recent studies have demonstrated the pivotal roles of genetic defects in the pathogenesis of CHDs, and a great number of genetic mutations have been associated with CHDs. Nevertheless, CHDs are a genetically heterogeneous disorder and the genetic basis underlying CHDs in an overwhelming majority of cases remains unclear. In the present study, the coding exons and flanking introns of the heart and neural crest derivatives expressed transcript 1 (HANDI) gene, which encodes a basic helix-loop-helix transcription factor crucial for cardiovascular development, were sequenced in 158 unrelated patients with CHDs, and a de novo heterozygous mutation, p.K132X, was identified in a patient with double outlet right ventricle (DORV), as well as ventricular septal defect. The nonsense mutation, which was predicted to produce a truncated HAND1 protein lacking 84 carboxyl-terminal amino
\end{abstract}

Correspondence to: Dr Xing-Biao Qiu or Dr Yi-Qing Yang, Department of Cardiology, Shanghai Chest Hospital, Shanghai Jiao Tong University, 241 West Huaihai Road, Shanghai 200030, P.R. China

E-mail: qxingbiao@sina.cn

E-mail: dryyq@tongji.edu.cn

*Contributed equally

Key words: congenital heart defects, genetics, transcription factor, $H A N D 1$, reporter gene assay acids, was absent in 600 control chromosomes. Functional analyses revealed that the HAND1 K132X mutant had no transcriptional activity. Furthermore, the mutation disrupted the synergistic activation between HAND1 and GATA binding protein 4 (GATA4), another cardiac core transcription factor causally linked to CHDs. To the best of our knowledge, this is the first report on the association of HANDI loss-of-function mutation with an enhanced susceptibility to DORV in humans. These findings expand the phenotypic spectrum linked to HAND1 mutations, suggesting potential implications for the development of novelo prophylactic and therapeutic strategies for DORV.

\section{Introduction}

Congenital heart defects (CHDs), a series of developmental anomalies in the structures of the heart and the great endothoracic blood vessels, encompassing ventricular septal defect (VSD), atrial septal defect, tetralogy of Fallot, double outlet right ventricle (DORV), transposition of the great arteries, pulmonary atresia and persistent truncus ateriosus, are the most common form of birth defects in humans, with an estimated prevalence of $1 \%$ in live births worldwide (1). It was reported that in 2013, there were $>34$ million individuals living with CHDs worldwide (2). Severe CHDs may result in reduced exercise performance and quality of life (3-6), fetal brain injury and neurodevelopmental delay $(7,8)$, pulmonary hypertension and Eisenmenger syndrome (9), cardiac enlargement and heart failure (10,11), cardiac arrhythmias and sudden cardiac death (12-14). In fact, CHDs are responsible for approximately $30 \%$ of all birth defect-related deaths (1). Globally in 2010, CHDs led to approximately 223,000 deaths (15). Although great advances in cardiac surgical techniques and intensive care have allowed the overwhelming majority of children with CHDs to survive into adulthood, unfortunately, the late morbidity and mortality rates are still high in the survivors (16-18). Therefore, CHDs have laid a heavy economic 
burden on patients and healthcare systems, and this burden is anticipated to be even heavier in the future due to an increasing number of CHDs in adults (16-18). Despite the important clinical significance, the causes of CHDs among most patients remain largely unclear.

It has been previously reported that non-inherited modifiable factors, including maternal illnesses, nutritional deficiencies, and exposure to drugs, toxicants or polluted air during the first trimester of pregnancy may confer an increased vulnerability to CHDs (19). However, a growing body of evidence strongly suggests that genetic defects are the predominant cause of CHDs, and mutations in a great number of genes, particularly those coding for transcription factors essential for cardiovascular morphogenesis, including NK2 homeobox (NKX2)-5, NKX2-6, GATA binding protein (GATA)4, GATA5, GATA6, T-Bo (TBX)1, TBX5, TBX20, paired like homeodomain 2 (PITX2) and heart and neural crest derivatives expressed transcript (HAND)2, have been associated with various CHDs (20-57). Nevertheless, CHDs are a genetically heterogeneous disorder, and the genetic basis underlying CHDs in an overwhelming majority of cases remains to be elucidated.

The HAND subset of basic helix-loop-helix (bHLH) transcription factors is composed of two members, HAND1 and HAND2, which are required for the normal cardiovascular development in fish, chicks, rodents and humans (58). The HAND1 protein has a functionally important structural domain termed bHLH, which consists of a short stretch of basic amino acids followed by an amphipathic $\alpha$ helix, a loop and an additional $\alpha$ helix, and is required for binding to target gene DNA and protein-protein combinatorial interactions (59). A previous study demonstrated that HAND1 can directly activate the cardiac $A N F$ promoter, alone or in synergy with transcriptionally cooperative partners, including GATA4, myocyte enhancer factor 2 (MEF2) and HAND2 (60). In chicks, HAND1 and HAND2 are both expressed in the bilateral heart primordia and subsequently throughout the primitive tubular heart, as well as its derivatives during embryonic genesis, and the treatment of chick embryos with HAND1 and HAND2 antisense oligonucleotides has revealed that either oligonucleotide alone has no effect on embryonic development, whereas together they arrest development at the looping heart tube stage (61). In mice, HAND1 is highly expressed in distinct regions of the linear heart tube during embryogenesis and, after looping, becomes localized to both primary heart fields, specifically in the outer curvature of the presumptive left ventricle and the developing outflow tract, and also at a lower level in the outer curvature of the right ventricle (62). Mice lacking Handl suffer from defective cardiac looping, failed chamber septation, anomalous ventricular myocardial differentiation and early embryonic lethality resulting from cardiac failure $(63,64)$. Mouse embryos homozygous for the cardiac-specific Handl-null allele present diverse cardiac deformations, including membranous VSD, overriding aorta and hyperplastic atrioventricular valves, and DORV (65). In humans, HAND1 is expressed in cardiac tissues within both ventricles (66), and mutations in HANDI have been causally linked to hypoplastic hearts and cardiac septal defects (67-69). However, the prevalence and spectrum of $H A N D 1$ mutations in other cohorts of patients with various CHDs remain to be investigated.
Thus, in this study, the coding exons and flanking introns of the HANDl gene, which encodes a basic helix-loop-helix transcription factor crucial for cardiovascular development, were sequenced in 158 unrelated patients with CHDs. We identified a de novo heterozygous mutation, $\mathrm{p} . \mathrm{K} 132 \mathrm{X}$ in a patient with DORV. Thus, this mutation may be associated with an enhanced susceptibility to DORV. Our findings may provide new insight into the pathogenesis of DORV and CHDs at the genetic level.

\section{Materials and methods}

Ethics. This study was conducted in conformity with the ethical principles for medical research outlined in the Declaration of Helsinki. The study protocol was approved by the local institutional Ethics Committee of Tongji Hospital, Tongji University, Shanghai, China [approval no. LL(H)-09-07], and written informed consent was obtained from the patients or their guardians prior to the study.

Study population. A cohort of 158 unrelated patients ( 87 males and 71 females, with an average age of 3.3 years) with non-syndromic CHDs was recruited from the Chinese Han population. The available relatives of the $\mathrm{CHD}$ cases were also enlisted. All patients underwent a comprehensive clinical evaluation, including medical history, complete physical examination, 12-lead electrocardiogram and two-dimensional transthoracic echocardiography with color flow Doppler. Cardiac catheterization, angiography and cardiac magnetic resonance imaging were carried out only when indicated. The cardiac phenotype was confirmed by echocardiography in all patients with CHDs. Patients with known chromosomal abnormalities or other recognized syndromic CHDs were excluded from the study. A total of 300 healthy subjects (162 males and 138 females, with an average age of 3.2 years), who were matched to the patietns with CHD in age, gender and ethnicity, were enrolled as controls. All the control individuals underwent transthoracic echocardiography and their cardiac morphologic structures were shown to be normal.

Mutational analysis of HAND1. Peripheral venous blood samples were drawn from the study participants and the genomic DNA was isolated from leukocytes using the Wizard Genomic DNA Purification Kit (Promega Corp., Madison, WI, USA) according to the manual of procedure. The referential genomic DNA sequence of HANDl was derived from GenBank (GenBank ID: NC_000005.10), an online nucleotide database at the National Center for Biotechnology Information (NCBI; http://www.ncbi.nlm.nih.gov/nucleotide/). With the aid of the online Primer-BLAST program (https://www.ncbi.nlm.nih. gov/tools/primer-blast/index.cgi?ORGANISM=9606\&INPUT_ SEQUENCE=NC_000005.10\&LINK_LOC=nuccore\&PRIMER5_ START=154474972\&PRIMER3_END=154478264), the primers used to amplify the coding exons and splicing junction sites of HAND1 by polymerase chain reaction (PCR) were designed as shown in Table I. PCR was carried out using HotStar Taq DNA Polymerase (Qiagen, Hilden, Germany) on a Veriti Thermal Cycler (Applied Biosystems, Foster, CA, USA). The amplicons were fractionated by electrophoresis on a $2 \%$ agarose gel and then purified with the QIAquick Gel Extraction kit (Qiagen, Hilden, Germany). The purified amplicons were 
Table I. Primers used for the amplification of the coding regions and splicing junction sites of the HANDl gene.

\begin{tabular}{lrrr}
\hline Coding exon & Forward primer $\left(5^{\prime} \rightarrow 3^{\prime}\right)$ & Reverse primer $\left(5^{\prime} \rightarrow 3^{\prime}\right)$ & Product size $(\mathrm{bp})$ \\
\hline 1 & GAGCGGCGTTAATAGGGCTG & TTCGACTACCTGCATGGCCT & 666 \\
2 & GGAACTCCGCGCATAAAGGC & CGTGCGATCCAAGTGTGTGG & 478 \\
\hline
\end{tabular}

bp, base pairs.

PCR-sequenced under an ABI PRISM 3130 XL DNA Analyzer (Applied Biosystems) with BigDye ${ }^{\circledR}$ Terminator v3.1 Cycle Sequencing kits (Applied Biosystems). The DNA sequences were analyzed with the DNA Sequencing Analysis Software v5.1 (Applied Biosystems). For an identified sequence variance, the Human Gene Mutation Database (HGMD; http://www.hgmd. cf.ac.uk/), the 1000 Genomes Project (1000GP; http://www. 1000genomes.org/data) database, the NCBI's single nucleotide polymorphism (SNP; http://www.ncbi.nlm.nih.gov/snp) database and PubMed (http://www.ncbi.nlm.nih.gov/pubmed) database were consulted to confirm its novelty.

Alignment of multiple HAND1 protein sequences among species. The amino acid sequences of the HAND1 protein in humans were aligned with those in the chimpanzee, monkey, cattle, mouse, rat, fowl, fruitfly and frog using MUSCLE, an online program (http://www.ncbi.nlm.nih.gov/homologene), in order to show the evolutionary conservation for an altered amino acid.

Expression plasmids and site-directed mutagenesis. The recombinant expression plasmid, HAND1-pcDNA3.1, which contains the full-length cDNA of human $H A N D 1$, was constructed as previously described (69). The identified mutation was introduced into the wild-type HAND1-pcDNA3.1 plasmid by site-directed mutagenesis using a QuickChange II XL Site-Directed Mutagenesis kit (Stratagene, La Jolla, CA, USA) and a complementary pair of primers, and was verified by sequencing. The expression plasmid GATA4-pSSRa and the ANF-luciferase reporter (ANF-luc) plasmid, which contains the 2600-bp 5'-flanking region of the $A N F$ gene and expresses the Firefly luciferase, were kind gifts from Dr Ichiro Shiojima at Chiba University School of Medicine (Chiba, Japan).

Cell culture, DNA transfection and luciferase assays. HeLa and NIH3T3 cells were cultured in Dulbecco's modified Eagle's medium supplemented with $10 \%$ fetal bovine serum, and plated at a density of $1 \times 10^{5}$ cells per well on 24-well plates $24 \mathrm{~h}$ prior to transfection. Transfection was performed using Lipofectamine ${ }^{\circledR} 2000$ reagent (Invitrogen Life Technologies, Carlsbad, CA, USA) following the manufacturer's instructions. The internal control vector pGL4.75 (Promega Corp.), which expresses the Renilla luciferase, was co-transfected in transfection assays to normalize transfection efficiency. For the transfection of HeLa cells, $1.0 \mu \mathrm{g}$ of empty pcDNA3.1 vector, $1.0 \mu \mathrm{g}$ of wild-type HAND1-pcDNA3.1, $1.0 \mu \mathrm{g}$ of mutant HAND1-pcDNA3.1, $0.5 \mu \mathrm{g}$ of wild-type HAND1-pcDNA3.1, or $0.5 \mu \mathrm{g}$ of wild-type HAND1-pcDNA3.1 plus $0.5 \mu \mathrm{g}$ of mutant HAND1-pcDNA3.1 were used in combination with
Table II. Clinical characteristics of the patients with congenital heart defects.

\begin{tabular}{|c|c|c|}
\hline Parameters & No. or mean & $\%$ or range \\
\hline Male/female & $87 / 71$ & $55 / 45$ \\
\hline Age, years & 3 & $0-12$ \\
\hline Positive family history of CHDs & 11 & 7 \\
\hline \multicolumn{3}{|l|}{$\begin{array}{l}\text { Distribution of distinct } \\
\text { forms of CHDs }\end{array}$} \\
\hline Isolated CHDs & 95 & 60 \\
\hline VSD & 31 & 20 \\
\hline ASD & 19 & 12 \\
\hline PDA & 13 & 8 \\
\hline PS & 10 & 6 \\
\hline DORV & 5 & 3 \\
\hline TGA & 4 & 3 \\
\hline PTA & 3 & 2 \\
\hline HLV & 3 & 2 \\
\hline $\mathrm{PA}$ & 2 & 1 \\
\hline TAPVC & 2 & 1 \\
\hline $\mathrm{CoA}$ & 2 & 1 \\
\hline CAC & 1 & 1 \\
\hline Complex CHDs & 63 & 40 \\
\hline TOF & 25 & 16 \\
\hline $\mathrm{VSD}+\mathrm{ASD}$ & 15 & 9 \\
\hline DORV + VSD & 13 & 8 \\
\hline VSD + PDA & 8 & 5 \\
\hline PTA + VSD & 1 & 1 \\
\hline TGA + VSD & 1 & 1 \\
\hline \multicolumn{3}{|l|}{ Incidence of arrhythmias } \\
\hline Atrioventricular block & 8 & 5 \\
\hline Atrial fibrillation & 5 & 3 \\
\hline \multicolumn{3}{|l|}{ Treatment } \\
\hline Surgical repair & 92 & 58 \\
\hline Percutaneous closure & 32 & 22 \\
\hline Follow-up & 31 & 20 \\
\hline
\end{tabular}

ASD, atrial septal defect; CAC, common atrioventricular canal; CHDs, congenital heart defects; CoA, coarctation of the aorta; DORV, double outlet right ventricle; HLV, hypoplastic left ventricle; PA, pulmonary atresia; PDA, patent ductus arteriosus; PS, pulmonary stenosis; PTA, persistent truncus arteriosus; TAPVC, total abnormal pulmonary venous connection; TGA, transposition of the great arteries; TOF, tetralogy of Fallot; VSD, ventricular septal defect. 


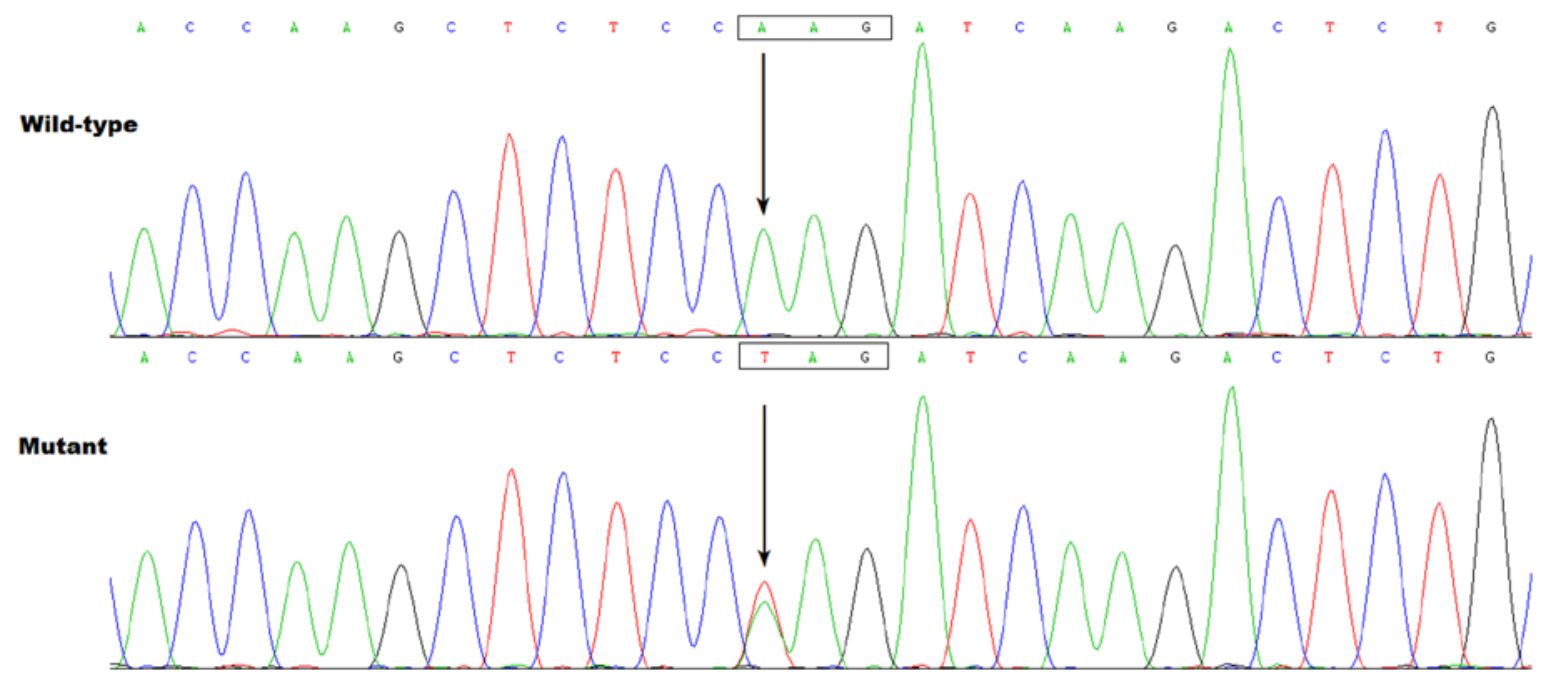

Figure 1. Sequence electropherograms exhibiting the HAND1 mutation and its wild-type. The arrows indicate the heterozygous nucleotides of T/A in the mutation carrier (mutant) or the homozygous nucleotides of A/A in the corresponding control individual (wild-type). The rectangle marks the nucleotides comprising a codon of $H A N D 1$.

$1.0 \mu \mathrm{g}$ of ANF-luc and $0.04 \mu \mathrm{g}$ of pGL4.75. For the transfection of NIH3T3 cells, the same amount $(0.5 \mu \mathrm{g})$ of plasmid DNA (empty pcDNA3.1 vector, wild-type HAND1-pcDNA3.1, GATA4-pSSRa or mutant HAND1-pcDNA3.1) was used alone or in combination, in the presence of $1.0 \mu \mathrm{g}$ of ANF-luc and $0.04 \mu \mathrm{g}$ of pGL 4.75 . The transfected cells were incubated for $48 \mathrm{~h}$ at $37^{\circ} \mathrm{C}$ with $5 \% \mathrm{CO}_{2}$, then washed and lysed using $1 \mathrm{X}$ passive lysis buffer provided by the Dual-Glo luciferase reporter assay kit (Promega Corp.). The Firefly and Renilla luciferase activities were measured using the Dual-Glo luciferase reporter assay kit (Promega Corp.) according to the manufacture's instructions using a GloMax ${ }^{\circledR} 96$ Luminometer (Promega Corp.). The activity of the ANF promoter was expressed as the fold activation of the Firefly luciferase value relative to the Renilla luciferase value. At least 3 independent transfection experiments, all of which were conducted in triplicate, were performed to calculate average values and standard deviations.

Statistical analysis. Statistical analyses were performed using the SPSS version 17.0 software package (SPSS, Inc., Chicago, IL, USA). Data are expressed as the means and standard deviation, unless otherwise indicated. The numeric variables were compared between 2 groups using the Student's unpaired t-test. A comparison of the categorical variables between 2 groups was made using Pearson's $\chi^{2}$ test or Fisher's exact test where appropriate. A two-tailed value of $\mathrm{P}<0.05$ was considered to indicate a statistically significant difference.

\section{Results}

Baseline clinical features of the study subjects. In this study, 158 unrelated patients with isolated CHDs (87 males and 71 females, with an average age of 3.3 years) were clinically evaluated in contrast with 300 ethnically-matched, unrelated healthy individuals (162 males and 138 females, with an average age of 3.2 years). All the patients had echocardiographically documented CHDs. Of the 158 patients with CHD, 11 (approximately 7\%) had a positive family history of CHDs.
The control individuals were physically and mentally healthy with no structural cardiac defects confirmed by echocardiogram, and they had a negative family history of CHDs. There were no significant differences between the patient and control groups as regards demographic characteristics, including age, gender and ethnicity. The baseline clinical characteristics of the 158 unrelated patients with CHDs are presented in Table II.

Discovery of a de novo HANDI mutation. By PCR sequencing, a heterozygous mutation in $H A N D I$ was identified in one of the 158 unrelated patients with isolated CHDs, with a mutational prevalence of approximately $0.63 \%$. Specifically, a substitution of thymine (T) for adenine (A) in the first nucleotide of codon 132 (c.394A $>\mathrm{T})$, predicting the conversion of the codon coding for lysine $(\mathrm{K})$ into a stop codon $(\mathrm{X})$ at amino acid position 132 (p.K132X), was discovered in a 5-month-old boy affected with congenital DORV, as well as VSD, who had no family history of CHDs. The nonsense mutation was neither found in the mutation carrier's healthy parents, nor detected in the 300 unrelated control individuals, indicating it is a de novo mutation. The sequence chromatograms showing the heterozygous HANDl mutation of c.394A>T, as well as its control sequence are shown in Fig. 1. A schematic diagram of HAND1 showing the bHLH structural domain and the location of the identified mutation is shown in Fig. 2. The identified HAND1 mutation c.394A $>\mathrm{T}$ has not been reported in the HGMD, 1000GP, SNP and PubMed databases (accessed on September 12, 2016), suggesting that it is a novel mutation.

Alignment of multiple HAND1 protein sequences across species. Multiple alignments of the HAND1 protein sequences among various species displayed that the altered lysine at amino acid position 132 (p.K132) was completely conserved evolutionarily (Fig. 3).

No transcriptional activity of the mutant HAND1 protein. As shown in Fig. 4, dual-luciferase assays in the cultured HeLa cells revealed that the same amount $(1.0 \mu \mathrm{g})$ of wild-type and 
HAND1

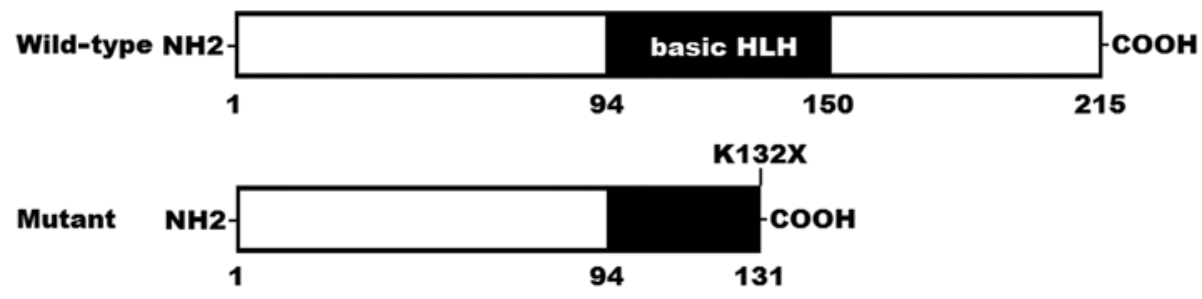

Figure 2. Schematic diagram depicting the HAND1 protein structures with the identified mutation indicated. The mutation identified in a patient with double outlet right ventricle as well as ventricular septal defect is shown above the structural domain. $\mathrm{NH} 2$, amino-terminus; bHLH, basic helix loop helix; COOH, carboxyl-terminus.

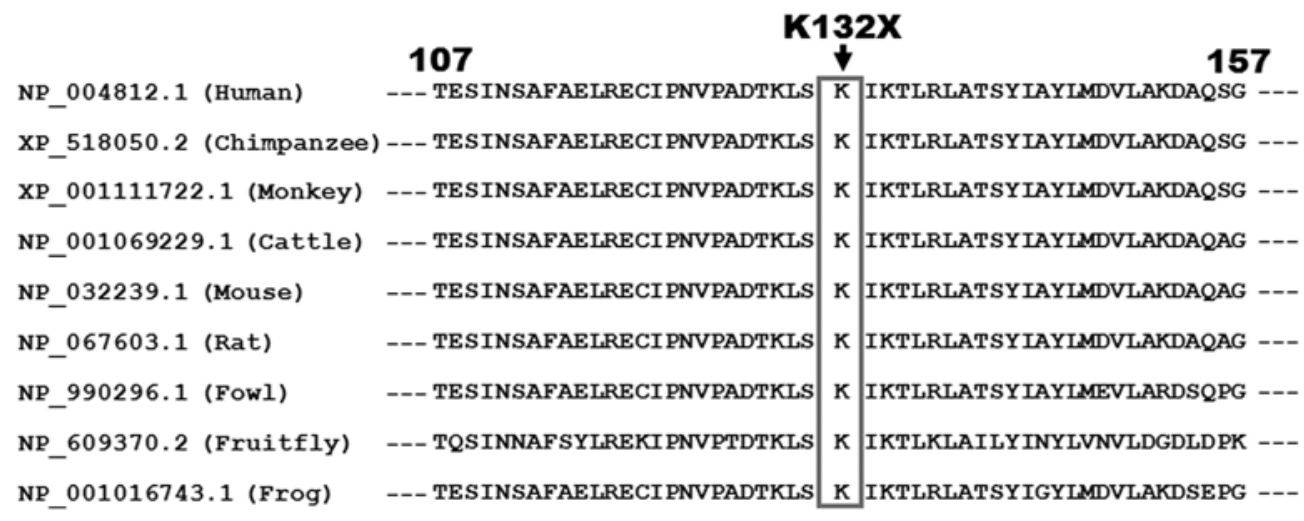

Figure 3. Alignment of multiple HAND1 protein sequences across species. The altered lysine at amino acid 132 (p.K132) is completely conserved evolutionarily among various species.

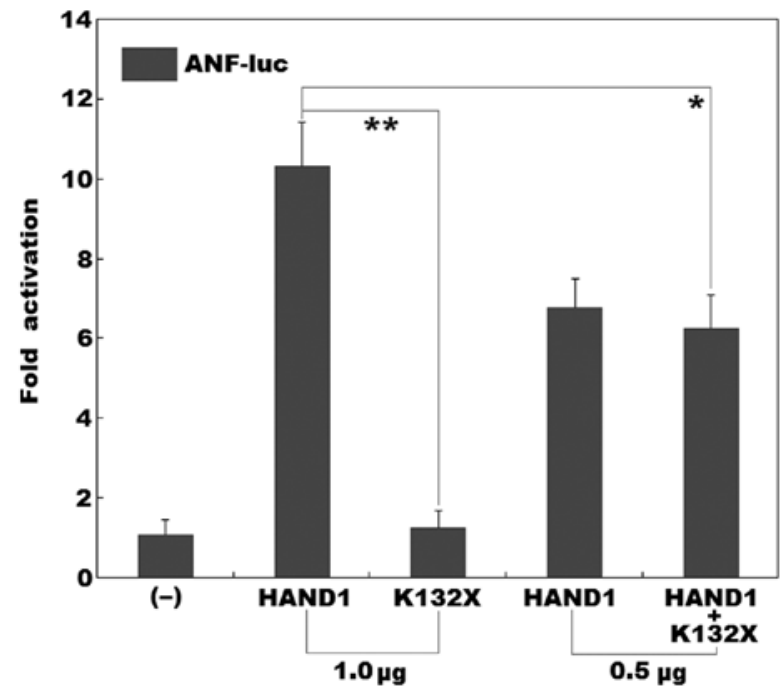

Figure 4. No transcriptional activity of the mutant HAND1 protein. HeLa cell transfection assays measuring activation of the $A N F$ promoter revealed that the K132X-mutant HAND1 protein had no transcriptional activity. Experiments were performed in triplicate, and mean and standard deviations are given. ${ }^{* *} \mathrm{P}<0.001,{ }^{*} \mathrm{P}<0.01$.

K132X-mutant HAND1-pcDNA3.1 plasmids transcriptionally activated the $A N F$ promoter by approximately 10 -fold and approximately 1-fold, respectively. When $0.5 \mu \mathrm{g}$ of wild-type HAND1-pcDNA3.1 was used together with the same amount $(0.5 \mu \mathrm{g})$ of $132 \mathrm{X}$-mutant HAND1-pcDNA3.1, the induced activation of the $A N F$ promoter was approximately 6 -fold.

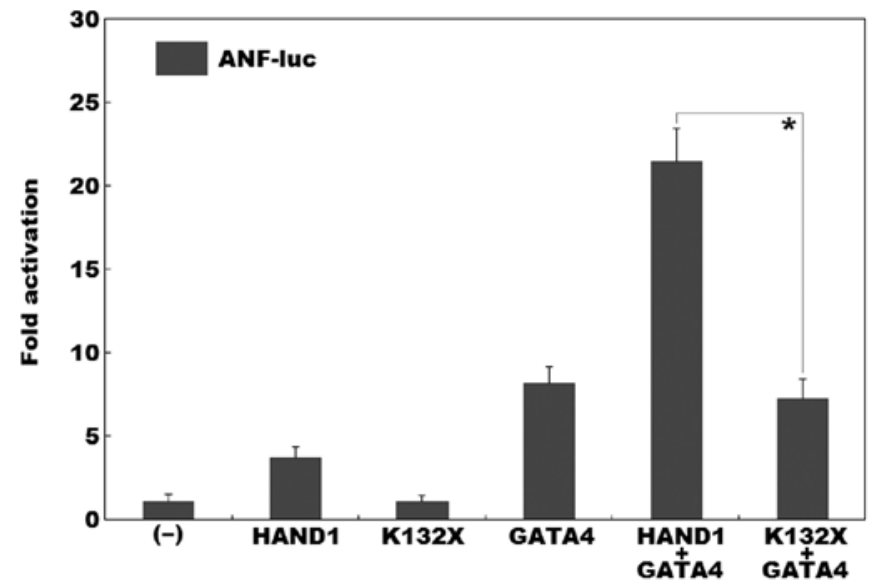

Figure 5. Synergistic transcriptional activation disrupted by the mutation. NIH3T3 cell transfection assays measuring synergistic activation of the ANF promoter between HAND1 and GATA4 unveiled disrupted synergistic activation by the K132X mutation. Experiments were performed in triplicate, and mean and standard deviations are given. ${ }^{*} \mathrm{P}<0.001$.

Synergistic transactivational failure caused by the mutation. As shown in Fig. 5, dual-luciferase assays in the cultured NIH3T3 cells revealed that the same amount $(0.5 \mu \mathrm{g})$ of wild-type and K132X-mutant HAND1 activated the $A N F$ promoter by approximately 4-fold and approximately 1 -fold, respectively; while in the presence of $0.5 \mu \mathrm{g}$ of wild-type GATA4, the same amount $(0.5 \mu \mathrm{g})$ of wild-type and K132X-mutant HAND1 
activated the $A N F$ promoter by approximately 22 -fold and approximately 7 -fold, respectively.

\section{Discussion}

In the current study, a novel heterozygous mutation, p.K132X, was identified in a patient with isolated DORV, as well as VSD. The nonsense mutation, which was absent in the 600 reference chromosomes, altered the amino acid that was completely conserved evolutionarily across species, and was predicted to generate a truncated protein with partial bHLH domain left. Functional tests revealed that the K132-mutant HAND1 protein had no transcriptional activation of the $A N F$ promoter. Furthermore, the mutation abrogated the synergistic activation of the $A N F$ promoter between HAND1 and GATA4. Therefore, it is likely that the identified HANDI mutation predisposes to DORV, as well as VSD.

In humans, the HANDl gene, as the $e H A N D$ gene, is located at chromosome $5 \mathrm{q} 33$, coding for a transcription factor protein of 215 amino acids. In this study, the HAND1 mutation identified in a patient with CHD was predicted to generate a truncated protein losing the partial bHLH domain; thus, it is reasonably anticipated to disable $H A N D 1$. Functional analyses substantiated that the mutant HANDI lost the transcriptional activation of the $A N F$ promoter. Furthermore, the mutation disrupted the synergistic activation between HAND1 and GATA4, another cardiac core transcription factor previously associated with CHDs in humans (70). These findings strongly suggest that haploinsufficiency caused by the HAND1 mutation is probably an alternative pathological mechanism of CHDs.

Somatic or germline mutations in HANDl have been previously associated with various CHDs in humans (67-69). By direct PCR sequencing of the HANDI gene in human heart tissues derived from 31 unrelated patients with hypoplastic hearts, Reamon-Buettner et al (67) identified a common frameshift mutation (p.A126fsX12) in 24 of 31 hypoplastic left or right ventricles. Luciferase assays revealed that the resulting mutant protein was unable to modulate the transcription of reporter genes, suggesting that functionally impaired HANDI leads to hypoplastic human hearts. Subsequently, Reamon-Buettner et al (67) sequenced HANDl in a cohort of 68 malformed hearts affected primarily by septation defects, and detected 32 different nonsynonymous mutations, of which 12 are in the bHLH domain of HAND1. Functional analyses using yeast and mammalian cells have revealed that the transcriptional activity of HAND1 is reduced or abolished by certain mutations, suggesting that genetically compromised HANDI may also be responsible for septation defects of the human hearts. Chen et al (68) screened the coding regions of $H A N D 1$ in 498 unrelated individuals affected with non-syndromic CHDs, and found 2 novel non-synonymous mutations of p.G73S and p.K152N in 2 patients suffering from VSD, respectively. Yeast two-hybrid and liquid $\beta$-galactosidase assays indicated that both mutations increased the transcriptional activity of HAND1, probably by enhancing the capability of HAND1 to form homodimers. In this study, a de novo HAND1 mutation of p.K132X was discovered in a patient with DORV and VSD, thus expanding the clinical phenotypic spectrum linked to HANDI mutations. Taken collectively, these findings highlight the exquisite sensitivity of the developing cardiovascular system to the function of $H A N D 1$, suggesting a key role of HAND1 in human heart development and CHDs.

In conclusion, this study firstly associates HANDI loss-of-function mutation with enhanced susceptibility to DORV and VSD, which adds significant insight to the molecular pathogenesis underpinning CHDs, suggesting potential implications for precise diagnosis and genetic counseling of patients with CHD.

\section{Acknowledgements}

We are really grateful to the study participants for their dedication to the study. This study was supported by grants from the National Basic Research Program of China (no. 2012CB9668003), the National Natural Science Fund of China (nos. 81470372, 81270231, 81270161 and 31170791), the Key Program for Basic Research of Shanghai, China (no. 14JC1405500), the Natural Science Fund of Shanghai, China (no. 16ZR1432500), and the Fundamental Research Funds for the Central Universities (to $\mathrm{Li} \mathrm{Li}$ ).

\section{References}

1. Mozaffarian D, Benjamin EJ, Go AS, Arnett DK, Blaha MJ, Cushman M, de Ferranti S, Després JP, Fullerton HJ, Howard VJ, et al; American Heart Association Statistics Committee and Stroke Statistics Subcommittee: Heart disease and stroke statistics - 2015 update: A report from the American Heart Association. Circulation 131: e29-e322, 2015.

2. Global Burden of Disease Study 2013 Collaborators: Global, regional, and national incidence, prevalence, and years lived with disability for 301 acute and chronic diseases and injuries in 188 countries, 1990-2013: A systematic analysis for the Global Burden of Disease Study 2013. Lancet 386: 743-800, 2015.

3. Feltez G, Coronel CC, Pellanda LC and Lukrafka JL: Exercise capacity in children and adolescents with corrected congenital heart disease. Pediatr Cardiol 36: 1075-1082, 2015.

4. Rosenblum O, Katz U, Reuveny R, Williams CA and Dubnov-Raz G: Exercise performance in children and young adults after complete and incomplete repair of congenital heart disease. Pediatr Cardiol 36: 1573-1581, 2015.

5. Kahr PC, Radke RM, Orwat S, Baumgartner H and Diller GP: Analysis of associations between congenital heart defect complexity and health-related quality of life using a meta-analytic strategy. Int J Cardiol 199: 197-203, 2015.

6. DillerGP,Bräutigam A,Kempny A,Uebing A, Alonso-GonzalezR, Swan L, Babu-Narayan SV, Baumgartner H, Dimopoulos K and Gatzoulis MA: Depression requiring anti-depressant drug therapy in adult congenital heart disease: Prevalence, risk factors, and prognostic value. Eur Heart J 37: 771-782, 2016.

7. Sun L, Macgowan CK, Sled JG, Yoo SJ, Manlhiot C, Porayette P, Grosse-Wortmann L, Jaeggi E, McCrindle BW, Kingdom J, et al: Reduced fetal cerebral oxygen consumption is associated with smaller brain size in fetuses with congenital heart disease. Circulation 131: 1313-1323, 2015.

8. Marelli A,Miller SP,Marino BS, Jefferson AL and Newburger JW: Brain in congenital heart disease across the lifespan: The cumulative burden of injury. Circulation 133: 1951-1962, 2016.

9. Galiè N, Humbert M, Vachiery JL, Gibbs S, Lang I, Torbicki A, Simonneau G, Peacock A, Vonk Noordegraaf A, Beghetti M, et al: 2015 ESC/ERS Guidelines for the diagnosis and treatment of pulmonary hypertension: The Joint Task Force for the Diagnosis and Treatment of Pulmonary Hypertension of the European Society of Cardiology (ESC) and the European Respiratory Society (ERS): Endorsed by: Association for European Paediatric and Congenital Cardiology (AEPC), International Society for Heart and Lung Transplantation (ISHLT). Eur Heart J 37: 67-119, 2016. 
10. Stout KK, Broberg CS, Book WM, Cecchin F, Chen JM, Dimopoulos K, Everitt MD, Gatzoulis M, Harris L, Hsu DT, et al; American Heart Association Council on Clinical Cardiology, Council on Functional Genomics and Translational Biology, and Council on Cardiovascular Radiology and Imaging: Chronic Heart Failure in Congenital Heart Disease: A Scientific Statement From the American Heart Association. Circulation 133: 770-801, 2016.

11. Wald RM, Valente AM and Marelli A: Heart failure in adult congenital heart disease: Emerging concepts with a focus on tetralogy of Fallot. Trends Cardiovasc Med 25: 422-432, 2015.

12. McLeod CJ and Warnes C: Recognition and management of arrhythmias in adult congenital heart disease. Curr Opin Cardiol 31: 117-123, 2016

13. Priori SG, Blomström-Lundqvist C, Mazzanti A, Blom N, Borggrefe M, Camm J, Elliott PM, Fitzsimons D, Hatala R, Hindricks G, et al: 2015 ESC Guidelines for the management of patients with ventricular arrhythmias and the prevention of sudden cardiac death: The Task Force for the Management of Patients with Ventricular Arrhythmias and the Prevention of Sudden Cardiac Death of the European Society of Cardiology (ESC). Endorsed by: Association for European Paediatric and Congenital Cardiology (AEPC). Eur Heart J 36: 2793-2867, 2015.

14. Diller GP and Baumgartner H: Sudden cardiac death during exercise in patients with congenital heart disease: The exercise paradox and the challenge of appropriate counselling. Eur Heart J 37: 627-629, 2016

15. Lozano R, Naghavi M, Foreman K, Lim S, Shibuya K, Aboyans V, Abraham J, Adair T, Aggarwal R, Ahn SY, et al: Global and regional mortality from 235 causes of death for 20 age groups in 1990 and 2010: A systematic analysis for the Global Burden of Disease Study 2010. Lancet 380: 2095-2128, 2012.

16. van der Bom T, Zomer AC, Zwinderman AH, Meijboom FJ, Bouma BJ and Mulder BJ: The changing epidemiology of congenital heart disease. Nat Rev Cardiol 8: 50-60, 2011.

17. Tutarel O, Kempny A, Alonso-Gonzalez R, Jabbour R, Li W, Uebing A, Dimopoulos K, Swan L, Gatzoulis MA and Diller GP: Congenital heart disease beyond the age of 60: Emergence of a new population with high resource utilization, high morbidity, and high mortality. Eur Heart J 35: 725-732, 2014.

18. Niwa K: Adults with congenital heart disease transition. Curr Opin Pediatr 27: 576-580, 2015.

19. Jenkins KJ, Correa A, Feinstein JA, Botto L, Britt AE, Daniels SR, Elixson M, Warnes CA and Webb CL; American Heart Association Council on Cardiovascular Disease in the Young: Noninherited risk factors and congenital cardiovascular defects: current knowledge: a scientific statement from the American Heart Association Council on Cardiovascular Disease in the Young: endorsed by the American Academy of Pediatrics. Circulation 115: 2995-3014, 2007.

20. Andersen TA, Troelsen KL and Larsen LA: Of mice and men: Molecular genetics of congenital heart disease. Cell Mol Life Sci 71: 1327-1352, 2014

21. Homsy J, Zaidi S, Shen Y, Ware JS, Samocha KE, Karczewski KJ DePalma SR, McKean D, Wakimoto H, Gorham J, et al: De novo mutations in congenital heart disease with neurodevelopmental and other congenital anomalies. Science 350: 1262-1266, 2015.

22. Li Y, Klena NT, Gabriel GC, Liu X, Kim AJ, Lemke K, Chen Y, Chatterjee B, Devine W, Damerla RR, et al: Global genetic analysis in mice unveils central role for cilia in congenital heart disease. Nature 521: 520-524, 2015.

23. Guimier A, Gabriel GC, Bajolle F, Tsang M, Liu H, Noll A, Schwartz M, El Malti R, Smith LD, Klena NT, et al: MMP21 is mutated in human heterotaxy and is required for normal left-right asymmetry in vertebrates. Nat Genet 47: 1260-1263, 2015.

24. Racedo SE, McDonald-McGinn DM, Chung JH, Goldmuntz E, Zackai E, Emanuel BS, Zhou B, Funke B and Morrow BE: Mouse and human CRKL is dosage sensitive for cardiac outflow tract formation. Am J Hum Genet 96: 235-244, 2015.

25. Mlynarski EE, Sheridan MB, Xie M, Guo T, Racedo SE, McDonald-McGinn DM, Gai X, Chow EW, Vorstman J, Swillen A, et al; International Chromosome 22q11.2 Consortium: International Chromosome 22q11.2 Consortium: Copy-number variation of the glucose transporter gene SLC2A3 and congenital heart defects in the 22q11.2 deletion syndrome. Am J Hum Genet 96: 753-764, 2015.

26. Guo T, Chung JH, Wang T, McDonald-McGinn DM, Kates WR, Hawuła W, Coleman K, Zackai E, Emanuel BS and Morrow BE: Histone modifier genes alter conotruncal heart phenotypes in 22q11.2 deletion syndrome. Am J Hum Genet 97: 869-877, 2015.
27. Quintero-Rivera F, Xi QJ, Keppler-Noreuil KM, Lee JH, Higgins AW, Anchan RM, Roberts AE, Seong IS, Fan X, Lage $\mathrm{K}$, et al: MATR3 disruption in human and mouse associated with bicuspid aortic valve, aortic coarctation and patent ductus arteriosus. Hum Mol Genet 24: 2375-2389, 2015.

28. Sanchez-Castro M, Pichon O, Briand A, Poulain D, Gournay V, David A and Le Caignec C: Disruption of the SEMA3D gene in a patient with congenital heart defects. Hum Mutat 36: 30-33, 2015.

29. Theis JL, Zimmermann MT, Evans JM, Eckloff BW, Wieben ED, Qureshi MY, O'Leary PW and Olson TM: Recessive MYH6 mutations in hypoplastic left heart with reduced ejection fraction. Circ Cardiovasc Genet 8: 564-571, 2015.

30. Kassab K, Hariri H, Gharibeh L, Fahed AC, Zein M, El-Rassy I, Nemer M, El-Rassi I, Bitar F and Nemer G: GATA5 mutation homozygosity linked to a double outlet right ventricle phenotype in a Lebanese patient. Mol Genet Genomic Med 4: 160-171, 2015.

31. Perrot A, Schmitt KR, Roth EM, Stiller B, Posch MG, Browne EN, Timmann C, Horstmann RD, Berger F and Özcelik C: CCN1 mutation is associated with atrial septal defect. Pediatr Cardiol 36: 295-299, 2015

32. Wang J, Mao JH, Ding KK, Xu WJ, Liu XY, Qiu XB, Li RG, Qu XK, Xu YJ, Huang RT, et al: A novel NKX2.6 mutation associated with congenital ventricular septal defect. Pediatr Cardiol 36: 646-656, 2015.

33. Zheng J, Li F, Liu J, Xu Z, Zhang H, Fu Q, Wang J and Sun K: Investigation of somatic NKX2-5 mutations in Chinese children with congenital heart disease. Int J Med Sci 12: 538-543, 2015.

34. Pan Y, Wang ZG, Liu XY, Zhao H, Zhou N, Zheng GF, Qiu XB, Li RG, Yuan F, Shi HY, et al: A novel TBX1 loss-of-function mutation associated with congenital heart disease. Pediatr Cardiol 36: 1400-1410, 2015.

35. Zhao CM, Peng LY, Li L, Liu XY, Wang J, Zhang XL, Yuan F, Li RG, Qiu XB and Yang YQ: PITX2 loss-of-function mutation contributes to congenital endocardial cushion defect and Axenfeld-Rieger syndrome. PLoS One 10: e0124409, 2015.

36. Deng X, Pan H, Wang J, Wang B, Cheng Z, Cheng L, Zhao L, $\mathrm{Li} \mathrm{H}$ and Ma X: Functional analysis of two novel mutations in TWIST1 protein motifs found in ventricular septal defect patients. Pediatr Cardiol 36: 1602-1609, 2015.

37. Pan Y, Geng R, Zhou N, Zheng GF, Zhao H, Wang J, Zhao CM, Qiu XB, Yang YQ and Liu XY: TBX20 loss-of-function mutation contributes to double outlet right ventricle. Int J Mol Med 35: 1058-1066, 2015

38. Yang J, Zhu M, Wang Y, Hou X, Wu H, Wang D, Shen H, Hu Z and Zou J: Whole-exome sequencing identify a new mutation of MYH7 in a Chinese family with left ventricular noncompaction. Gene 558: 138-142, 2015.

39. Sifrim A, Hitz MP, Wilsdon A, Breckpot J, Turki SH, Thienpont B, McRae J, Fitzgerald TW, Singh T, Swaminathan GJ, et al; INTERVAL Study; UK10K Consortium; Deciphering Developmental Disorders Study: Distinct genetic architectures for syndromic and nonsyndromic congenital heart defects identified by exome sequencing. Nat Genet 48: 1060-1065, 2016.

40. Boyle L, Wamelink MM, Salomons GS, Roos B, Pop A Dauber A, Hwa V, Andrew M, Douglas J, Feingold M, et al: Mutations in TKT are the cause of a syndrome including short stature, developmental delay, and congenital heart defects. Am J Hum Genet 98: 1235-1242, 2016.

41. Li N, Subrahmanyan L, Smith E, Yu X, Zaidi S, Choi M, Mane S, Nelson-Williams C, Bahjati M, Kazemi M, et al: Mutations in the histone modifier PRDM6 are associated with isolated nonsyndromic patent ductus arteriosus. Am J Hum Genet 98: 1082-1091, 2016.

42. Fregeau B, Kim BJ, Hernández-García A, Jordan VK, Cho MT, Schnur RE, Monaghan KG, Juusola J, Rosenfeld JA, Bhoj E, et al: De novo mutations of RERE cause a genetic syndrome with features that overlap those associated with proximal $1 \mathrm{p} 36$ deletions. Am J Hum Genet 98: 963-970, 2016.

43. Priest JR, Osoegawa K, Mohammed N, Nanda V, Kundu R, Schultz K, Lammer EJ, Girirajan S, Scheetz T, Waggott D, et al: De novo and rare variants at multiple loci support the oligogenic origins of atrioventricular septal heart defects. PLoS Genet 12: e1005963, 2016.

44. Werner P, Latney B, Deardorff MA and Goldmuntz E: MESP1 mutations in patients with congenital heart defects. Hum Mutat 37: 308-314, 2016

45. LaHaye S, Corsmeier D, Basu M, Bowman JL, Fitzgerald-Butt S, Zender G, Bosse K, McBride KL, White P and Garg V: Utilization of whole exome sequencing to identify causative mutations in familial congenital heart disease. Circ Cardiovasc Genet 9: 320-329, 2016. 
46. Liu D, Liu QQ, Guan LH, Jiang X, Zhou DX, Beghetti M, Qu JM and Jing ZC: BMPR 2 mutation is a potential predisposing genetic risk factor for congenital heart disease associated pulmonary vascular disease. Int J Cardiol 211: 132-136, 2016.

47. Sun YM, Wang J, Qiu XB, Yuan F, Li RG, Xu YJ, Qu XK, Shi HY, Hou XM, Huang RT, et al: A HAND2 loss-of-function mutation causes familial ventricular septal defect and pulmonary stenosis. G3 (Bethesda) 6: 987-992, 2016.

48. Yoshida A, Morisaki H, Nakaji M, Kitano M, Kim KS, Sagawa K Ishikawa S, Satokata I, Mitani Y, Kato H, et al: Genetic mutation analysis in Japanese patients with non-syndromic congenital heart disease. J Hum Genet 61: 157-162, 2016.

49. Lu CX, Gong HR, Liu XY, Wang J, Zhao CM, Huang RT, Xue S and Yang YQ: A novel HAND2 loss-of-function mutation responsible for tetralogy of Fallot. Int J Mol Med 37: 445-451, 2016.

50. Cao Y, Wang J, Wei C, Hou Z, Li Y, Zou H, Meng M, Wang W and Jiang L: Genetic variations of NKX2-5 in sporadic atrial septal defect and ventricular septal defect in Chinese Yunnan population. Gene 575: 29-33, 2016.

51. Chen J, Qi B, Zhao J, Liu W, Duan R and Zhang M: A novel mutation of GATA4 (K300T) associated with familial atrial septal defect. Gene 575: 473-477, 2016.

52. Tong YF: Mutations of NKX2.5 and GATA4 genes in the development of congenital heart disease. Gene 588: 86-94, 2016.

53. Zhang X, Wang J, Wang B, Chen S, Fu Q and Sun K: A novel missense mutation of GATA4 in a Chinese family with congenital heart disease. PLoS One 11: e0158904, 2016.

54. Sun YM, Wang J, Qiu XB, Yuan F, Xu YJ, Li RG, Qu XK, Huang RT, Xue S and Yang YQ: PITX2 loss-of-function mutation contributes to tetralogy of Fallot. Gene 577: 258-264, 2016.

55. Zhou YM, Dai XY, Huang RT, Xue S, Xu YJ, Qiu XB and Yang YQ: A novel TBX2O loss of function mutation contributes to adult onset dilated cardiomyopathy or congenital atrial septal defect. Mol Med Rep 14: 3307-3314, 2016.

56. Li FF, Deng X, Zhou J, Yan P, Zhao EY and Liu SL: Characterization of human bone morphogenetic protein gene variants for possible roles in congenital heart disease. Mol Med Rep 14: 1459-1464, 2016.

57. Kelle AM, Bentley SJ, Rohena LO, Cabalka AK and Olson TM: Ebstein anomaly, left ventricular non-compaction, and early onset heart failure associated with a de novo $\alpha$-tropomyosin gene mutation. Am J Med Genet A 170: 2186-2190, 2016.

58. Thattaliyath BD, Livi CB, Steinhelper ME, Toney GM and Firulli AB: HAND1 and HAND2 are expressed in the adult-rodent heart and are modulated during cardiac hypertrophy. Biochem Biophys Res Commun 297: 870-875, 2002.
59. Reamon-Buettner SM, Ciribilli Y, Inga A and Borlak J: A loss-of-function mutation in the binding domain of HAND1 predicts hypoplasia of the human hearts. Hum Mol Genet 17: 1397-1405, 2008

60. Morin S, Pozzulo G, Robitaille L, Cross J and Nemer M: MEF2-dependent recruitment of the HAND1 transcription factor results in synergistic activation of target promoters. J Biol Chem 280: 32272-32278, 2005.

61. Srivastava D, Cserjesi P and Olson EN: A subclass of bHLH proteins required for cardiac morphogenesis. Science 270: 1995-1999, 1995.

62. Risebro CA, Smart N, Dupays L, Breckenridge R, Mohun TJ and Riley PR: Hand1 regulates cardiomyocyte proliferation versus differentiation in the developing heart. Development 133: 4595-4606, 2006.

63. Firulli AB, McFadden DG, Lin Q, Srivastava D and Olson EN Heart and extra-embryonic mesodermal defects in mouse embryos lacking the bHLH transcription factor Hand1. Nat Genet 18: 266-270, 1998.

64. Riley P, Anson-Cartwright L and Cross JC: The Hand1 bHLH transcription factor is essential for placentation and cardiac morphogenesis. Nat Genet 18: 271-275, 1998.

65. McFadden DG, Barbosa AC, Richardson JA, Schneider MD, Srivastava D and Olson EN: The Hand1 and Hand2 transcription factors regulate expansion of the embryonic cardiac ventricles in a gene dosage-dependent manner. Development 132: 189-201, 2005.

66. Natarajan A, Yamagishi H, Ahmad F, Li D, Roberts R, Matsuoka R, Hill S and Srivastava D: Human eHAND, but not dHAND, is down-regulated in cardiomyopathies. J Mol Cell Cardiol 33: 1607-1614, 2001.

67. Reamon-Buettner SM, Ciribilli Y, Traverso I, Kuhls B, Inga A and Borlak J: A functional genetic study identifies HAND1 mutations in septation defects of the human heart. Hum Mol Genet 18: 3567-3578, 2009.

68. Cheng Z, Lib L, Li Z, Liu M, Yan J, Wang B and Ma X: Two novel HAND1 mutations in Chinese patients with ventricular septal defect. Clin Chim Acta 413: 675-677, 2012.

69. Zhou YM, Dai XY, Qiu XB, Yuan F, Li RG, Xu YJ, Qu XK, Huang RT, Xue S and Yang YQ: HAND1 loss-of-function mutation associated with familial dilated cardiomyopathy. Clin Chem Lab Med 54: 1161-1167, 2016.

70. McCulley DJ and Black BL: Transcription factor pathways and congenital heart disease. Curr Top Dev Biol 100: 253-277, 2012. 